\title{
Optimization of extraction of phenolic compounds from Tokaji Aszú marc using response surface methodology
}

\section{SZILVIA BÁNVÖLGYI ${ }^{1 *}$ (D), ESZTER DUSZA ${ }^{1}$, FIINA K. NAMUKWAMBI², ISTVÁN KISS ${ }^{3}$, ÉVA STEFANOVITS-BÁNYAI ${ }^{4}$ and GYULA VATAI ${ }^{1}$}

${ }^{1}$ Department of Food Engineering, Faculty of Food Science, Szent István University, Hungary

${ }^{2}$ Department of Food Science and Technology, Faculty of Agriculture and Natural Resources, University of Namibia, Namibia

${ }^{3}$ Fitomark 94 Ltd., Tolcsva, Hungary

${ }^{4}$ Department of Applied Chemistry, Faculty of Food Science, Szent István University, Hungary

\section{CONFERENCE FULL PAPER}

Received: January 31, 2020 • Accepted: August 25, 2020

Published online: October 13, 2020

(C) 2020 The Author(s)

\begin{abstract}
Similarly to other industries wineries also increasingly attempt to minimize and utilize waste to protect our environment. The aim of this study was to determine the optimal parameters (temperature, solvent concentration, and time) of extracting total polyphenol content (TPC) from Tokaji Aszú marc using two different extraction solvents: ethanol-water and isopropanol-water (1:4 solid/liquid ratio). The extractions were achieved based on Central Composite Design with Response Surface Method (CCRD-RSM). The optimal extraction parameters in the case of ethanol-water solvent: $60{ }^{\circ} \mathrm{C}$ temperature, $59.5 \%$ ethanol concentration in solvent, $5 \mathrm{~h}$. At these parameters the probable TPC concentration is $23966.2 \mathrm{uM} \mathrm{GAE} / \mathrm{L}$. The optimal extraction parameters in the case of isopropanol-water solvent: $60{ }^{\circ} \mathrm{C}$ temperature, $52 \%$ ethanol concentration in solvent, $5 \mathrm{~h}$. At these parameters the probable TPC concentration is $7188.44 \mathrm{uM}$ $\mathrm{GAE} / \mathrm{L}$. In both cases the binary solvent was better than the mono-solvent. Ethanol-water solvent was more efficient than the isopropanol-water solvent.
\end{abstract}

*Corresponding author. E-mail: Banvolgyi.Szilvia@szie.hu 


\section{KEYWORDS}

extraction, grape marc, phenolics, ethanol, isopropanol

\section{INTRODUCTION}

Nile et al. (2013), Lafka et al. (2007), and Spigno et al. (2007) declared that grapes are among the fruits that have the highest content of phenolic compounds. Ignat et al. (2011), and Vatai et al. (2009) found that natural phenols have excellent properties as natural colorants and food preservatives. Polyphenol antioxidants are used as food additives to protect against food deterioration (Singh and Immanuel, 2014). The polyphenol content has many favorable effects on the human health, such as the inhibition of the oxidization of low-density lipoproteins and the anti-carcinogenic effects (Spigno et al., 2007; Bonilla et al., 1999). The grapes are also rich in antioxidants. Antioxidants are beneficial to health because they have protective role against oxidative stress. Antioxidants have an important role in preventing the development of many diseases such as cancer and coronary heart disease (Alía et al., 2003).

Wine production generates a huge amount of waste which is considered as unbeneficial and potentially causes environment problems. Therefore, there is a need for guidelines to manage this waste through technologies that minimize their environmental impact and lead to a sustainable use of resources similarly to other industries (Guida and Hannioui, 2016). However, due to the advancement of technology some wineries make an effort to minimize the remaining waste. The necessary development of innovation and effective valorization procedures has been implemented to reduce winery waste (Teixeira et al., 2014). Winery waste is regarded as a lowcost source of antioxidant and phenolic compounds (Spigno et al., 2007). Wine making residues include organic waste (grape marc, seeds, pulp and skin, grape stems, and leaves), wastewater, emission of greenhouse gases, and inorganic waste (Teixeira et al., 2014; Musee et al., 2007). In Hungary the most famous grape species is the Tokaji Aszú. The natural or induced development of noble rot is caused by the fungus Botrytis cinerea. There must be three basic conditions for the noble rot: (1) the grape should be in full maturity when the wet weather induces the growing of the fungi, (2) at the same time the grape should be intact and free from injury, and (3) a few days of rainy weather followed by a long and dry period (Eperjesi et al., 1998). Finding the optimal parameters for a certain process can improve the quality of final product (Varga et al., 2019). There is just scarce research which was carried out to optimize the yield of bioactive compounds extracted from Tokaji Aszú marc (winery waste). The industry does not use this material in notable volume. Some part of it is used in alcohol or grape seed oil production, however, the majority of it is not utilized.

In the present paper, organic waste (grape marc) was studied. This waste is generated during the production of must (grape juice) after pressing the whole fruits (Teixeira et al., 2014). Şahin et al. (2013), Mašković et al. (2016), and Chew et al. (2011) describe that different extraction conditions such as the type and concentration of the solvent, $\mathrm{pH}$, temperature and time, pressure, and the size of particles may significantly influence the quantitative parameters (total phenolic compounds) and qualitative parameters (antioxidant capacity) present in grapes byproduct. The objective of the present study was to find the optimal extraction parameters (time, temperature, solvent concentration) to maximize the retrieval of phenolics from Tokaji Aszú marc applying single stage solvent extraction. 


\section{MATERIALS AND METHODS}

\section{Material and chemicals}

The Fitomark Ltd. (Tolcsva) provided the Tokaji Aszú marc (grape type was Furmint), which was generated in 2016 and stored in a frozen state until the experiments.

Folin-Ciocalteu reagent was purchased from Merck KGaA. (Darmstadt, Germany), the gallic acid was obtained from Sigma-Aldrich, Chemicals Company (St. Louis, MO, USA). The methanol and sodium carbonate were purchased from Reanal Laborvegyszer Ltd. (Budapest, Hungary).

\section{Extraction procedure}

The carried-out extraction is based on a central composite design. Three parameters were changed during the extractions: the time of the extraction, the temperature, and the solvent concentration. Every parameter has a minimum, a central, and a maximum point (Table 1). The solvent-to-sample ratio was 4:1. Lauda Ecoline E100 Immersion Thermostat was used to keep the temperature at a constant level. Continuous stirring $(215 \mathrm{rpm})$ was used during extractions, the evaporation loss of the solvent was obviated by a cover. The extraction solvent contained distilled water and alcohol (ethanol or iso-propanol), in different ratios.

Response surface methodology (RSM) technique was used to optimize the extraction conditions aimed at maximum recovery of polyphenol. The RSM is an empirical statistical technique employed for multiple regression analysis using quantitative data. It uses multivariable data obtained from carefully designed experiments to resolve multivariable scenarios simultaneously (Şahin et al., 2013). The experiments were made in randomized order, starting, and finishing the experiment series with a center point run (Table 2).

The center point measurements were dispersed as evenly as possible throughout the design matrix and repeated 6 times. Design Expert 11.0 software was used for optimization of extractions parameters and statistical analysis. A second-order polynomial equation was used to calculate the predicted response.

\section{Analysis of total polyphenol content (TPC)}

TPC of each sample were analyzed according to Folin-Ciocalteu assay (Singleton and Rossi, 1965; Koczka et al., 2018). The sample solution (50 $\mu \mathrm{L}, 3$ replicates) was mixed with 1,250 $\mu \mathrm{L}$ Folin-Ciocalteu reagent and $200 \mu \mathrm{L}$ methanol-distilled water (4:1) solution. After exactly 1 minute, $1,000 \mu \mathrm{L} 0.7 \mathrm{M}$ sodium carbonate solution was added to the sample solution. The sample mixture was put in thermal bath which maintained the temperature at $50{ }^{\circ} \mathrm{C}$. The

Table 1. Range of coded and actual values of extraction parameters for Central Composite Design

\begin{tabular}{rcccc}
\hline & & & \multicolumn{2}{c}{ Solvent concentration } \\
\cline { 4 - 5 } Level & Temperature $\left({ }^{\circ} \mathrm{C}\right)$ & Time $(\mathrm{h})$ & Water $(\%)$ & Alcohol $(\%)$ \\
\hline-1 & 30 & 1 & 100 & 0 \\
0 & 45 & 3 & 50 & 50 \\
1 & 60 & 5 & 0 & 100 \\
\hline
\end{tabular}


Table 2. Central Composite Design of factors with coded and actual values

\begin{tabular}{|c|c|c|c|c|c|c|c|}
\hline \multirow[b]{2}{*}{ Treatment } & \multirow[b]{2}{*}{ Order } & \multicolumn{3}{|c|}{ The coded levels } & \multicolumn{3}{|c|}{ The actual values } \\
\hline & & Temp. & Conc. & Time & Temp $\left({ }^{\circ} \mathrm{C}\right)$ & Solv. conc. (v/v\%) & Time (h) \\
\hline 1. & 13. & 1 & 1 & 1 & 60 & 100 & 5 \\
\hline 2. & 12. & 1 & 1 & -1 & 60 & 100 & 1 \\
\hline 3. & 3. & 1 & -1 & 1 & 60 & 0 & 5 \\
\hline 4. & 9. & 1 & -1 & -1 & 60 & 0 & 1 \\
\hline 5. & 4. & -1 & 1 & 1 & 30 & 100 & 5 \\
\hline 6. & 7. & -1 & 1 & -1 & 30 & 100 & 1 \\
\hline 7. & 17. & -1 & -1 & 1 & 30 & 0 & 5 \\
\hline 8. & 6. & -1 & -1 & -1 & 30 & 0 & 1 \\
\hline 9. & 14. & 1 & 0 & 0 & 60 & 50 & 3 \\
\hline 10. & 10. & -1 & 0 & 0 & 30 & 50 & 3 \\
\hline 11. & 8. & 0 & 1 & 0 & 45 & 100 & 3 \\
\hline 12. & 2. & 0 & -1 & 0 & 45 & 0 & 3 \\
\hline 13. & 19. & 0 & 0 & 1 & 45 & 50 & 5 \\
\hline 14. & 16. & 0 & 0 & -1 & 45 & 50 & 1 \\
\hline 15. & 1. & 0 & 0 & 0 & 45 & 50 & 3 \\
\hline 16. & 5. & 0 & 0 & 0 & 45 & 50 & 3 \\
\hline 17. & 11. & 0 & 0 & 0 & 45 & 50 & 3 \\
\hline 18. & 15. & 0 & 0 & 0 & 45 & 50 & 3 \\
\hline 19. & 18. & 0 & 0 & 0 & 45 & 50 & 3 \\
\hline 20. & 20. & 0 & 0 & 0 & 45 & 50 & 3 \\
\hline
\end{tabular}

absorbance was measured at $760 \mathrm{~nm}$ after $5 \mathrm{~min}$ incubation. The calibration was done by using gallic acid as standard and gave $R^{2}$ value of 0.99 . TPC was calculated using the equation of standard curve considering the dilution factor and was expressed in $\mu \mathrm{M}$ equivalents of gallic acid $(\mathrm{GAE}) / \mathrm{L}$.

\section{RESULTS AND DISCUSSION}

It was necessary to investigate the extraction parameters in order to determine the best combination of variables for the total polyphenol content from Tokaji Aszú marc. RSM technique was used to optimize the extraction conditions aimed at maximum recovery of polyphenol. The experimental data in terms of total polyphenol content are shown in Table 3.

The effects of each factor and their interaction were calculated using Design Expert program (version 11.0.0). Fitting the data with various models and, subsequently, the analysis of variance (ANOVA) showed that total phenolic content was best described with quadratic polynomial model. The quadratic polynomial model was highly significant and sufficient to represent the actual relationship between the response and significant parameters with very low $P$-value $(<0.0001)$ (Table 4).

Predicted values of dependent variables were obtained from the regression model. Statistical analysis showed that some linear and quadratic coefficients of regression model were significant $(P<0.05)$ whereas the lack of fit was nonsignificant $(P \geq 0.05)$ which validates the model. In 
Table 3. Central Composite Design of factors with experimental values

\begin{tabular}{lcc}
\hline & & TPC (uM GAE/L) \\
\cline { 2 - 3 } Treatment & Ethanol-water & Isopropanol-water \\
\hline 1. & 14375.00 & 2511.26 \\
2. & 11087.50 & 1599.10 \\
3. & 6675.50 & 1454.05 \\
4. & 6262.50 & 1365.77 \\
5. & 7650.00 & 1240.99 \\
6. & 4925.00 & 1101.35 \\
7. & 4100.00 & 1013.51 \\
8. & 2187.50 & 681.08 \\
9. & 26200.00 & 7274.77 \\
10. & 10550.00 & 3211.71 \\
11. & 13000.00 & 1828.83 \\
12. & 5200.00 & 1689.19 \\
13. & 24087.50 & 7310.81 \\
14. & 10325.00 & 3148.65 \\
15. & 16350.00 & 6378.38 \\
16. & 14750.00 & 5189.19 \\
17. & 11962.50 & 5018.02 \\
18. & 15737.50 & 6378.38 \\
19. & 18687.50 & 5189.19 \\
20. & 10875.00 & 5018.02 \\
\hline
\end{tabular}

both cases (using ethanol-water or iso-propanol-water solvent) the interaction coefficients were not significant, so the model was reduced. Finally, it contains only the linear and quadratic coefficients (Table 4).

The final regression equations (Eqs. (1) and (2))with linear and square coefficients in terms of actual factors:

For ethanol-water solvent:

$$
Y(\sqrt{(\mathrm{TPC})})=-0.0665+1.18 \dot{s} A+1.93 \dot{s} B+5.27 \dot{s} C-0.016 \dot{s} B^{2}
$$

For iso-propanol-water solvent:

$$
Y(\sqrt{(\mathrm{TPC})})=7.32+0.45 \dot{s} A+1.47 \dot{s} B+2.42 \dot{s} C-0.014 \dot{s} B^{2}
$$

where $A$ is the temperature $\left(30-60{ }^{\circ} \mathrm{C}\right), B$ is the alcohol concentration in the solvent $(0-100$ $\mathrm{v} / \mathrm{v} \%)$ and $C$ is the extraction time $(1-5 \mathrm{~h})$.

The relationship between extraction parameters and total polyphenol content were investigated by response surface plots selecting two independent values while remaining one at zero level. The highest total polyphenol content was observed at higher temperature (Fig. 1). High temperatures might have increased the diffusion and solubility rate of many compounds resulting higher extraction rate in phenolic compounds (Şahin et al., 2013). In both cases the binary solvent (1:1) was better than mono-solvent. According to the model the total polyphenol 
Table 4. ANOVA table for reduced quadratic models for ethanol-water and isopropanol-water solvent

\begin{tabular}{|c|c|c|c|c|c|c|c|c|c|c|}
\hline \multirow[b]{2}{*}{ Source } & \multicolumn{5}{|c|}{ Using ethanol-water solvent } & \multicolumn{5}{|c|}{ Using isopropanol-water solvent } \\
\hline & $\begin{array}{l}\text { Sum of } \\
\text { squares }\end{array}$ & $d f$ & $\begin{array}{l}\text { Mean } \\
\text { square }\end{array}$ & $F$-value & $P$-value & $\begin{array}{l}\text { Sum of } \\
\text { squares }\end{array}$ & $d f$ & $\begin{array}{c}\text { Mean } \\
\text { square }\end{array}$ & $F$-value & $P$-value \\
\hline Model & 14814.63 & 4 & 3703.66 & 23.44 & $<0.0001$ & 7017.44 & 4 & 1754.36 & 44.36 & $<0.0001$ \\
\hline A-Temp & 3123.67 & 1 & 3123.67 & 19.77 & 0.0005 & 455.12 & 1 & 455.12 & 11.51 & 0.0040 \\
\hline B-Solv conc & 2343.98 & 1 & 2343.98 & 14.84 & 0.0016 & 73.76 & 1 & 73.76 & 1.86 & 0.1922 \\
\hline C-Time & 1108.86 & 1 & 1108.86 & 7.02 & 0.0182 & 234.93 & 1 & 234.93 & 5.94 & 0.0277 \\
\hline$B^{2}$ & 8238.13 & 1 & 8238.13 & 52.15 & $<0.0001$ & 6253.63 & 1 & 6253.63 & 158.11 & $<0.0001$ \\
\hline Residual & 2369.61 & 1.53 & 157.97 & & & 593.27 & 15 & 39.55 & & \\
\hline Lack of fit & 1641.39 & 10 & 164.14 & 1.13 & 0.4759 & 497.13 & 10 & 49.71 & 2.59 & 0.1530 \\
\hline Pure error & 728.22 & 5 & 145.64 & & & 96.14 & 5 & 19.23 & & \\
\hline Cor Total & 17184.24 & 19 & & & & 7610.71 & 19 & & & \\
\hline
\end{tabular}




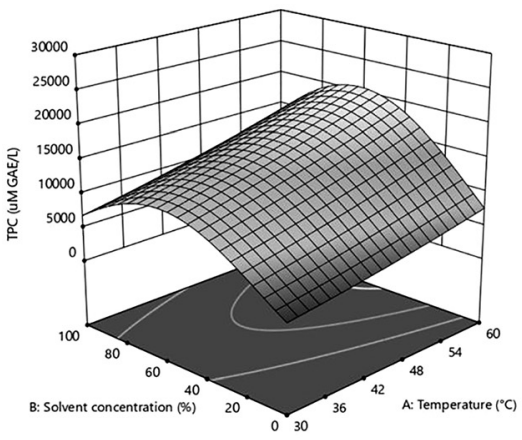

(a)

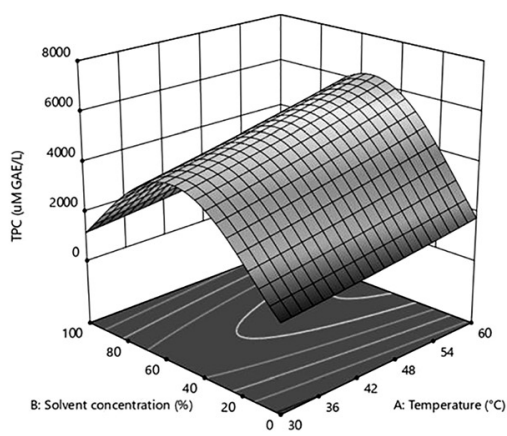

(b)

Fig. 1. Response surface plots showing the effect of solvent concentration and temperature on the polyphenols yield (uM GAE/L) from Tokaji Aszú marc waste while the time kept at coded zero level. (a) Using ethanol-water solvent. (b) Using isopropanol-water solvent

content in the extracts is predicted to decrease above $60 \%(\mathrm{v} / \mathrm{v})$ of alcohol content in the extraction solvent. Chew et al. (2011) reported similar results. Ethanol-water solvent was more efficient than the isopropanol-water solvent.

An increase in temperature has greater effect than an increase in extraction time on total polyphenol concentration in Tokaji Aszú marc extracts using ethanol-water solvent. A slight increase in TPC concentration can be observed in $5 \mathrm{~h}$, but after an increase in temperature the TPC concentration increased by 2-2.5 times (Fig. 2a). However, the effect of changing extraction time was significant for extracting phenolic compounds. In the case of isopropanol-water solvent the same trend was found.

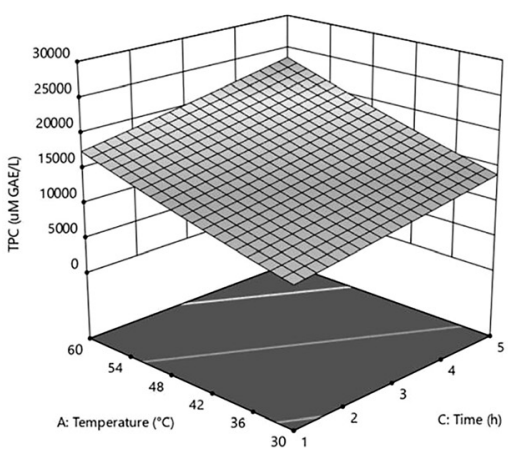

(a)

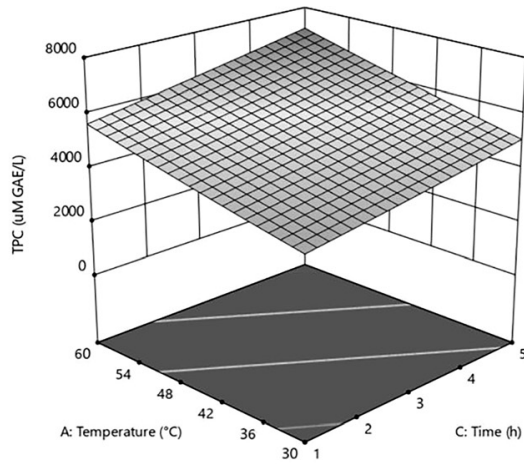

(b)

Fig. 2. Response surface plots showing the effect of temperature and time on the polyphenols yield (uM GAE/L) from Tokaji Aszú marc waste while the solvent concentration kept at coded zero level. (a) Using ethanol-water solvent. (b) Using isopropanol-water solvent 
The optimal extraction parameters in the case of ethanol-water solvent: $60{ }^{\circ} \mathrm{C}$ temperature, $59.5 \%$ ethanol concentration in solvent, $5 \mathrm{~h}$. With these parameters the probable TPC concentration is $23966.2 \mathrm{uM} \mathrm{GAE} / \mathrm{L}$. The optimal extraction parameters in the case of isopropanolwater solvent: $60{ }^{\circ} \mathrm{C}$ temperature, $52 \%$ ethanol concentration in solvent, $5 \mathrm{~h}$. With these parameters the probable TPC concentration is $7188.44 \mathrm{uM} \mathrm{GAE} / \mathrm{L}$. The optimal parameters can vary in other ranges of parameters.

\section{CONCLUSIONS}

The polyphenols were extracted from Tokaji Aszú marc waste following twenty selected combinations of temperature, solvent concentration, and extraction time. A second order model was developed to predict the polyphenol content. Ethanol-water solvent was more effective than isopropanol-water solvent. In the future we would like to continue the experiments with a new design with a narrower interval of parameters $\left(40-60{ }^{\circ} \mathrm{C}\right.$ temperature, $3-5 \mathrm{~h}$ extraction time and $25-75 \mathrm{v} / \mathrm{v} \%$ alcohol content in extraction solvent) using real solvent mixtures for extractions. The present study helps with the utilization of Tokaji Aszú marc waste and with the optimization of extraction parameters in maximizing the recovery of polyphenols. This optimization process provides valuable data which can be utilized in process design and industrial scale-up operations.

\section{ACKNOWLEDGMENTS}

This project was supported by the European Union and co-financed by the European Social Fund (Grant agreement no. EFOP-3.6.3-VEKOP-16-2017-00005); and by the ÚNKP-17-2-IISZIE-44 New National Excellence Program of the Ministry of Human Capacities.

\section{REFERENCES}

Alía, M., Horcajo, C., Bravo, L., and Goya, L. (2003). Effect of grape antioxidant dietary fiber on the total antioxidant capacity and the activity of liver antioxidant enzymes in rats. Nutrition Research, 23(9): 1251-1267.

Bonilla, F., Mayen, M., Merida, J., and Medina, M. (1999). Extraction of phenolic compounds from red grape marc for use as food lipid antioxidants. Food Chemistry, 66(2): 209-215.

Chew, K.K., Khoo, M.Z., Ng, S.Y., Thoo, Y.Y., Mustapha, W.A.W., and Ho, C.W. (2011). Effect of ethanol concentration, extraction time and extraction temperature on the recovery of phenolic compounds and antioxidant capacity of Orthosiphon stamineus extracts. International Food Research Journal, 18(4): 1427-1435.

Eperjesi, I., Kállay, M., and Magyar, I. (1998). Rothadási folyamatok a szőlőn. In: Récsey Antónia (szerk.), Borászat. Mezőgazda Kiadó, Budapest, pp. 459-465. 
Guida, M.Y. and Hannioui, A. (2016). A review on thermochemical treatment of biomass: Pyrolysis of olive mill wastes in comparison with other types of biomass. Progress in Agricultural Engineering Sciences, 12(1): $1-23$.

Ignat, I., Volf, I., and Popa, V.I. (2011). A critical review of methods for characterisation of polyphenolic compounds in fruits and vegetables. Food Chemistry, 126(4): 1821-1835.

Koczka, N., Stefanovits-Bányai, É., and Ombódi, A. (2018). Total polyphenol content and antioxidant capacity of rosehips of some Rosa species. Medicines, 5(3): 84-94.

Lafka, T., Sinanoglou, V., and Lazos, E.S. (2007). On the extraction and antioxidant activity of phenolic compounds from winery wastes. Food Chemistry, 104(3): 1206-1214.

Mašković, P.Z., Diamanto, L.D., Cvetanović, A., Radojković, M., Spasojević, M.B., and Zengin, G. (2016). Optimization of the extraction process of antioxidants from orange using response surface methodology. Food Analytical Methods, 9(5): 1436-1443.

Musee, N., Lorenzen, L., and Aldrich, C. (2007). Cellar waste minimization in the wine industry: A systems approach. Journal of Cleaner Production, 15(5): 417-431.

Nile, S.H., Kim, S.H., Ko, E.Y., and Park, S.W. (2013). Polyphenolic content and antioxidant properties of different grape (V. vinifera, V. labrusca, and V. hybrid) cultivars. BioMed Research International, 2013: 718065 .

Şahin, S., Aybastier, O., and Işik, E. (2013). Optimisation of ultrasonic-assisted extraction of antioxidant compounds from Artemisia absinthium using response surface methodology. Food Chemistry, 141(2): 1361-1368.

Singh, S. and Immanuel, G. (2014). Extraction of antioxidants from fruit peels and its utilization in paneer. Journal of Food Processing \& Technology, 5(7): 349.

Singleton, V.L. and Rossi, J.A. (1965). Colorimetry of total phenolics with phosphomolybdic-phosphotungstic acid reagents. American Journal of Enology and Viticulture, 16: 144-158.

Spigno, G., Tramelli, L., and De Faveri, D.M. (2007). Effects of extraction time, temperature and solvent on concentration and antioxidant activity of grape marc phenolics. Journal of Food Engineering, 81(1): 200-208.

Teixeira, A., Baenas, N., Dominguez-Perles, R., Barros, A., Rosa, E., Moreno, D.A., and Garcia-Viguera, C. (2014). Natural bioactive compounds from winery by-products as health promoters: Overview. International Journal of Molecular Sciences, 15(9): 15638-15678.

Varga, Á., Gáspár, I., Juhász, R., Ladányi, M., Hegyes-Vecseri, B., Kókai, Z., and Márki, E. (2019). Beer microfiltration with static turbulence promoter: Sum of ranking differences comparison. Journal of Food Process Engineering, 42(1): e12941.

Vatai, T., Skerget, M., and Knez, Z. (2009). Extraction of phenolic compounds from elderberry and different grape marc varieties using organic solvents and or supercritical carbon dioxide. Journal of Food Engineering, 90(2): 246-254.

Open Access. This is an open-access article distributed under the terms of the Creative Commons Attribution 4.0 International License (https://creativecommons.org/licenses/by/4.0/), which permits unrestricted use, distribution, and reproduction in any medium, provided the original author and source are credited, a link to the CC License is provided, and changes - if any - are indicated. (SID_1) 